\title{
Влияние обработки поверхности частиц технического углерода на адсорбцию синтетического каучука
}

\author{
Эльтеков А.Ю., Эльтекова Н.А., Эльтеков Ю.А.
}

ФАНО России ФГБУН Институт физической химии и электрохимии им. А.Н.Фрумкина РАН, Москва

Поступила в редакцию 31.01.2017 г.

\begin{abstract}
Изучена адсорбция олигобутадиенового каучука с гидроксильными концевыми группами из разбавленных растворов в н-гептане на частицах технического углерода, подвергнутых термической обработке. Показано изменение химии поверхности частиц исходного технического углерода под действием различной температуры и времени обработки в токе водорода. Оценено влияние химии поверхности частиц технического углерода на характер и энергетику взаимодействия макромолекул синтетического каучука с исходной и обработанной поверхностями технического углерода.
\end{abstract}

Ключевые слова: жидкофазная адсорбция, синтетический каучук, технический углерод

\section{The influence of surface chemistry of carbon black on adsorption of oligobutadienes rubber}

\author{
Eltekov A.Yu., Eltekova N.A., Eltekov Yu.A. \\ FANO of Russia Frumkin Institute of Physical Chemistry and Electrochemistry, \\ Russian Academy of Sciences, Moscow
}

\begin{abstract}
In this work we have studied the adsorption of oligobutadiene rubber (synthetic rubber) on native carbon black in comparison to heat-treated samples. Statical (batch) method has been used to determine isotherms of adsorption. Experimental error was less then 3\%. We found that thermal treatment of native carbon black increases adsorption of synthetic rubber from diluted $n$-heptane solution. Obtained isotherms of adsorption allow us to calculate distribution coefficients and differential Helmholtz energy for studied systems. In comparison to native carbon black, heat-treated samples showed the higher adsorption performance due to specific interactions at the solid-liquid interface.
\end{abstract}

Keywords: liquid phase adsorption, synthetic rubber, carbon black

\section{Введение}

Технический углерод благодаря своим уникальным свойствам находит широкое применение в промышленности. Основное количество выпускаемого технического углерода используется в производстве шин. В небольших объемах технический углерод используется в лакокрасочной промышленности и в производстве резино-технических изделий в качестве чёрного пигмента, замедлителя «старения» пластмасс, компонента, придающего пластмассам специальные свойства (электропроводность, способность поглощать различное излучение) [1-4].

Свойства композиционных полимерных материалов на основе технического углерода в основном определяются взаимодействием макромолекул полимерного 
связующего с частицами технического углерода в присутствии растворителя или пластификатора $[2,3,5,6]$.

При взаимодействии макромолекул полимерного связующего с поверхностью частиц твердого тела (адсорбента) прочность адсорбционных связей определяется химическим составом и морфологией поверхностных слоев адсорбента, а также химическим строением и конформацией макромолекулярных цепей и функциональных концевых групп адсорбированного полимерного связующего [7-15].

Для создания и оптимизации свойств полимерных композиционных материалов на основе технического углерода крайне важно изучение закономерностей процесса взаимодействия макромолекул полимерного связующего с поверхностью наполнителя и управление этим процессом путем модифицирования поверхности частиц технического углерода [16-18].

В настоящей работе при 298 К изучена и описана в рамках монослойной модели адсорбция синтетического каучука из разбавленных растворов в н-гептане частицами технического углерода, подвергнутых различной термической обработке с целью выяснения влияния химии поверхности наполнителя на характер взаимодействия с макромолекулами синтетического каучука.

\section{Эксперимент}

Образец олигомерного синтетического каучука - олигобутадиеновый каучук с гидроксильными концевыми группами со средневесовой молекулярной массой $M_{w}=2206$ и степенью полидисперсности $M_{w} / M_{n}=1.4$ был синтезирован на Ярославском заводе СК (Ярославль, РФ) [19].

В качестве сорбентов были использованы образцы технического углерода ПМ-100, поверхность которых была обработана различными способами. Образец С-2 был получен из исходного образца технического углерода ПМ-100 (образец С-1) путем термической обработки в токе водорода при $1000 \mathrm{~K}$ с целью удаления кислородсодержащих функциональных групп. Образец технического углерода (C-3) был получен при окислении исходного технического углерода ПМ-100 в аппарате с псевдоожиженным слоем. Окисление проводилось в токе воздуха при температуре $573 К$ в течение 30 мин. Образцы технического углерода были подготовлены в НПО «Техуглерод» (Ярославль, РФ) [16]. Условия обработки и характеристики исследованных образцов технического углерода приведены в табл. 1.

Таблица 1. Условия обработки и характеристики образцов технического углерода: температура $T$ и время $t$ обработки, удельная поверхность $S$, содержание $\mathrm{O}_{2}$ и количество функциональных групп $N$.

\begin{tabular}{|c|c|c|c|c|c|c|c|c|}
\hline \multirow[b]{2}{*}{ Образец } & \multirow[b]{2}{*}{$T, \mathrm{~K}$} & \multirow[b]{2}{*}{$\begin{array}{c}t, \\
\text { мин }\end{array}$} & \multirow[b]{2}{*}{$\begin{array}{c}S, \\
\mathrm{M}^{2} / \Gamma\end{array}$} & \multirow[b]{2}{*}{$\begin{array}{c}\mathrm{O}_{2}, \\
\%\end{array}$} & \multicolumn{4}{|c|}{$\mathrm{N}$, мкг-экв/ $\mathrm{M}^{2}$} \\
\hline & & & & & $\begin{array}{l}\text { Карбок } \\
\text { сильные }\end{array}$ & Фенольные & $\begin{array}{c}\text { Хинон } \\
\text { ные }\end{array}$ & $\begin{array}{l}\text { Лакто } \\
\text { новые }\end{array}$ \\
\hline C-1 & - & - & 95 & 1.25 & 0.12 & 0.42 & 3.44 & 1.16 \\
\hline C-2 & 1000 & 60 & 95 & - & - & - & - & - \\
\hline C-3 & 573 & 30 & 95 & 2.80 & 0.13 & 0.23 & 11.60 & 1.88 \\
\hline
\end{tabular}

Из табл. 1 видно, что данная обработка поверхности частиц технического углерода, проведенная в настоящей работе, не влияет на величину удельной поверхности исследуемых образцов, но существенно влияет на содержание кислорода и со- 
став поверхностных функциональных групп обработанных образцов технического углерода.

Изучение процесса взаимодействия макромолекул синтетического каучука из разбавленных растворов в н-гептане с поверхностью образцов технического углерода проводили при 298 К в статических условиях $[8,14,15]$. В пробирки с притертыми пробками помещали по 0.3 г адсорбента и $4 \mathrm{~cm}^{3}$ раствора каучука, затем пробирки помещали в аппарат для встряхивания. Равновесную концентрацию каучука в объемном растворе определяли с помощью жидкостного интерферометра ЛИР-2 (ЛОМО, С-Петербург).

Величину адсорбции каучука как избыток по Гиббсу Г рассчитывали по формуле:

$$
\Gamma=\frac{V}{S m_{a}}\left(C_{o}-C\right),
$$

где $V$ - объем раствора каучука, $m_{a}$ - масса и $S$ - удельная поверхность адсорбента, $C_{0}$ и $C$ - исходная и равновесная концентрации раствора каучука, соответственно. Ошибка определения концентрации раствора каучука составляла не более $3 \%$ для области концентраций $0.1<C<10 \mathrm{Mг} / \mathrm{cm}^{3}$.

\section{Обсуждение результатов}

Обработка различными способами поверхности частиц технического углерода позволяет изменять химию поверхности частиц технического углерода и, таким образом, управлять процессом взаимодействия макромолекул связующего с частицами технического углерода [3, 10, 20-22]. На рис. 1а приведены изотермы адсорбции макромолекул синтетического каучука из разбавленных растворов в н-гептане исходным образцом С-1 и образцами C-2, C-3 технического углерода, поверхность которых подвергалась термической обработке.

Следует отметить, что экспериментальные изотермы адсорбции макромолекул синтетического каучука из растворов в н-гептане образцами технического углерода имеют форму типичную для изотерм избыточной адсорбции низкомолекулярных веществ из растворов $[5,7]$. На всех трех образцах технического углерода наблюдается положительная адсорбция макромолекул синтетического каучука из растворов в н-гептане.

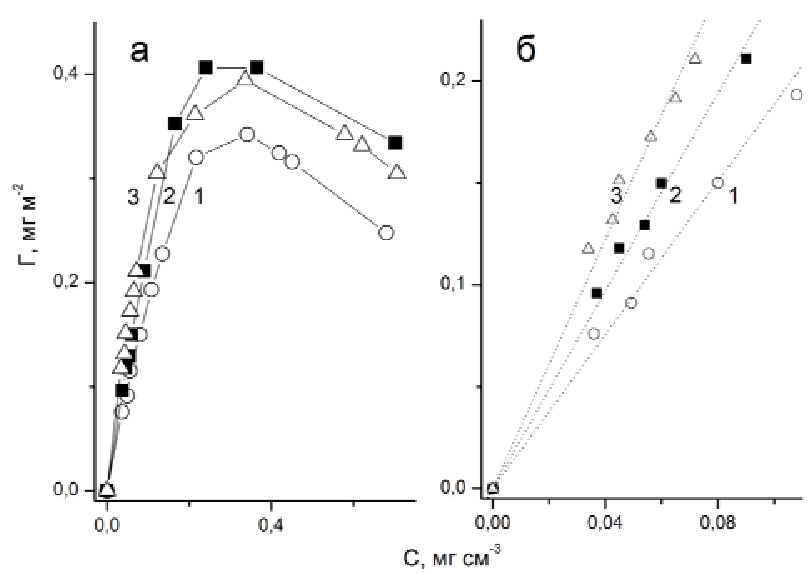

Рис. 1. Изотермы (а) и начальные участки изотерм (б) адсорбции синтетического каучука из разбавленных растворов в н-гептане образцами технического углерода С-1 (1), C-2 (2) и С-3 (3). 
Из рис. видно, что удаление кислородсодержащих функциональных групп с поверхности исходного образца технического углерода С-1 приводит к увеличению крутизны подъема изотермы адсорбции каучука образцом С-2 и к увеличению максимальной величины адсорбции. Окисление исходного образца технического углерода также приводит к увеличению крутизны подъема изотермы адсорбции каучука образцом С-3, однако наблюдается снижение максимальных величин адсорбции каучука образцом C-3, по сравнению с образцом C-2.

На рис. $1 б$ приведены начальные участки изотерм адсорбции макромолекул синтетического каучука из разбавленных растворов в н-гептане образцами технического углерода C-1, C-2 и С-3. Из рис. видно, что в начальной области равновесных концентраций изотермы адсорбции каучука на этих трех образцах технического углерода практически линейны и могут быть описана уравнением изотермы адсорбции Генри, что позволяет оценить значения $K_{H}$ - констант Генри для изученных адсорбционных систем

$$
K_{H}=\frac{\Gamma}{C}, \quad \text { при } C \rightarrow 0,
$$

Сопоставление значений величин адсорбции $\Gamma_{0,05}$ при равновесной концентрации $C=0.05$ мг $/ \mathrm{cm}^{3}$ и значений $K_{H}$ (табл. 2) для адсорбции макромолекул каучука на образцах технического углерода, различающихся способом обработки поверхности, дает возможность количественно оценить прочность адсорбционной связи адсорбат-адсорбент (каучук-технический углерод).

Таблица 2. Значения величины адсорбции $\Gamma_{0,05}$ при равновесной концентрации $C=0.05 \mathrm{мг} / \mathrm{cm}^{3}$ и $K_{H}$ - константы Генри для изотерм адсорбции синтетического каучука из растворов в н-гептане образцами технического углерода, температура $298 \mathrm{~K}$

\begin{tabular}{|c|c|c|c|}
\hline Образец & Тип поверхности & $\Gamma_{0,05}, \mathrm{M \Gamma} / \mathrm{m}^{2}$ & $K_{H}, \mathrm{~cm}^{3} / \mathrm{m}^{2}$ \\
\hline $\mathrm{C}-1$ & Исходная & 0.09 & $1.8 \pm 0.1$ \\
\hline $\mathrm{C}-2$ & $1000 \mathrm{~K}, 60$ мин & 0.12 & $2.4 \pm 0.1$ \\
\hline $\mathrm{C}-3$ & $\begin{array}{c}\text { Окисленная в токе воздуха, } \\
573 К, 30 \text { мин }\end{array}$ & 0.15 & $3.1 \pm 0.2$ \\
\hline
\end{tabular}

Анализ табл. 2 показал, что при адсорбции каучука из растворов в н-гептане наибольшая энергия взаимодействия макромолекул каучука проявляется с окисленной поверхностью образца технического углерода C-3. Удаление кислородсодержащих функциональных групп путем термической обработки поверхности образца технического углерода С-2 приводит к снижению энергии взаимодействия макромолекул каучука с поверхностью этого образца технического углерода. Самые низкие значения констант Генри наблюдаются при взаимодействии макромолекул каучука с поверхностью образца исходного технического углерода $\mathrm{C}-1$. При анализе полученных значений констант Генри следует учитывать конкурентный характер взаимодействия молекул растворителя (н-гептана) в адсорбционной системе каучук-н-гептантехнический углерод, который также изменяется при обработке поверхности адсорбента.

Такое поведение макромолекул каучука при адсорбции из растворов в нгептане на поверхности образцов технического углерода, различающихся химией поверхности, можно объяснить различной природой межмолекулярных взаимодействий на границе раздела фаз. Жидкофазная адсорбция молекул и макромолекул на поверхности углеродных адсорбентов обусловлена в основном дисперсионными межмолекулярными взаимодействиями на границе раздела фаз $[3,5,7,9]$. При ад- 
сорбции каучука исходным образцом технического углерода $\mathrm{C}-1$, на поверхности которого присутствуют кислородсодержащие функциональные группы, наряду с дисперсионным проявляется специфическое межмолекулярное взаимодействие гидроксильных групп макромолекул каучука с поверхностными группами образца технического углерода C-1 [14, 15, 20-22].

Удаление поверхностных кислородсодержащих групп с поверхности образца технического углерода С-2 способствует усилению дисперсионного взаимодействия макромолекул каучука с поверхностью образца $\mathrm{C}-2$, что приводит к увеличению энергии взаимодействия макромолекул каучука по сравнению с образцом исходного технического углерода С-1.

При адсорбции на поверхности окисленного образца технического углерода C-3 макромолекулы синтетического каучука, имеющие концевые гидроксильные группы, способные проявлять специфическое взаимодействие с кислородсодержащими группами поверхности образца С-3, наблюдается заметное увеличение энергии их взаимодействия по сравнению с образцами С-1 и С-2.

Изменение суммарной энергии Гельмгольца $\Delta F$ при взаимодействии макромолекул каучука с адсорбентом в процессе адсорбции рассчитывали по уравнению

$$
\Delta F=-R T \ln K_{p},
$$

где $R$ - газовая постоянная, $T$ - температура опыта, $K_{p}$ - коэффициент распределения макромолекул полимера между адсорбционным и объемным растворами.

Величины $K_{p}$ вычисляли как отношение $\frac{C_{a}}{C}$ концентраций полимера в $C_{a}-$ адсорбционном и $C$ - объемном растворах, соответственно

$$
K_{p}=\frac{C_{a}}{C},
$$

Концентрацию вещества $C_{a}$ в адсорбционном растворе определяли в рамках монослойной модели адсорбционного слоя как [21-24],

$$
C_{a}=\frac{\Gamma S+C V_{a}}{V_{a}},
$$

Тогда уравнение (4) принимает вид

$$
K_{p}=\frac{\Gamma S}{C V_{a}}+1,
$$

где адсорбционный объем $V_{a}=S \tau, \tau$ - усредненная толщина адсорбционного слоя, или

$$
K_{p}=\frac{K_{H}}{\tau_{a}}+1
$$

В табл. 3 приведены экспериментально полученные $\widetilde{A}_{\max }$ - максимальные величины адсорбции и вычисленные значения $K_{p}$ - коэффициентов распределения и $\Delta F$ - изменения суммарной энергии Гельмгольца при адсорбции макромолекул каучука из растворов в н-гептане образцами технического углерода.

Анализ табл. 3 показал, что, при адсорбции каучука из растворов в н-гептане на всех трех образцах технического углерода, избыток макромолекул полимера наблюдается в адсорбционном растворе, по сравнению с объемным раствором, на что указывают высокие значения коэффициентов $K_{p}$. При взаимодействии макромолекул каучука с поверхностями исходного технического углерода $\mathrm{C}-1$ и окисленного технического углерода C-3 из растворов в н-гептане могут возникать специфические межмолекулярные взаимодействия, по типу водородных связей, с кислородсодер- 
жащими функциональными группами поверхности этих образцов и концевыми гидроксильными группами макромолекул каучука. В случае образца С-3 это взаимодействие проявляется сильнее, что подтверждается значениями $K_{p}$ и $\Delta F$, превышающими эти значения для образца С-1.

Таблица 3. Значения $\widetilde{A}_{\max }, K_{\partial}$ и $\Delta F$ для адсорбции макромолекул каучука из растворов в н-гептане образцами технического углерода

\begin{tabular}{|c|c|c|c|c|}
\hline Образец & Тип поверхности & $\widetilde{A}_{\max }$, мг м $^{-2}$ & $K_{\partial}$ & $\Delta F$ (кДж моль $^{-1}$ ) \\
\hline $\mathrm{C}-1$ & Исходная & 0.33 & 2300 & -18 \\
\hline $\mathrm{C}-2$ & 1000 К, 60 мин & 0.40 & 3000 & -19 \\
\hline $\mathrm{C}-3$ & $\begin{array}{c}\text { Окисленная в токе воз- } \\
\text { духа, 573К, } \\
\text { 30 мин }\end{array}$ & 0.38 & 3900 & -20 \\
\hline
\end{tabular}

Как видно из табл. 3, избыток макромолекул каучука в адсорбционном растворе для образца С-3 наибольший и превышает значения $K_{p}$ для образцов С-1 и С-2. Кроме того, для образца $\mathrm{C}-3$ характерны наибольшие значения $\Delta F$. Удаление гидроксильных групп с поверхности образца технического углерода C-2 способствует усилению дисперсионного взаимодействия как молекул растворителя так и макромолекул каучука с поверхностью этого образца. Однако более крупные макромолекулы каучука преимущественно адсорбируются образцом С-2, вытесняя молекулы нгептана из адсорбционного слоя, на что указывают более высокие значения $K_{p}$, по сравнению с образцом С-1. Анализ табл. 3 показал, что влияние конкуренции молекул растворителя (н-гептана) на суммарную энергию адсорбции каучука образцами технического углерода с обработанной поверхностью практически не заметно, при этом вычисленные значения $\Delta F$ - изменения суммарной энергии Гельмгольца близки для всех изученных систем.

\section{Заключение}

Для изученных адсорбционных систем, включающих синтетический каучук, технический углерод и растворитель, вычислены константы уравнения изотермы адсорбции, $K_{p}$ - коэффициенты распределения макромолекул каучука между поверхностной (адсорбционной) и объемной фазами, а также $\Delta F$ - изменения свободной энергии каучука при взаимодействии каучука с образцами технического углерода.

Показано, что термическая обработка поверхности частиц технического углерода существенно влияет на характер и энергию взаимодействия макромолекул каучука с частицами технического углерода. Удаление кислородсодержащих функциональных групп с поверхности образца технического углерода $\mathrm{C}-2$ приводит к росту значений $K_{p}$ и $\Delta F$ относительно образца исходного технического углерода C-1 за счет увеличения вклада дисперсионной составляющей в суммарную энергию адсорбции макромолекул каучука. Окисление поверхности образца С-3 приводит к увеличению $K_{p}$ и $\Delta F$, по сравнению с образцами С-1 и С-2, за счет увеличения вклада специфической составляющей в суммарную энергию адсорбции макромолекул каучука. 


\section{Список литературы}

1. Carbon Black, Science and Technology. / Eds. by Donnet J.B., Bansal R.C., Wang M.J./ New York.: Marcel Dekker. 1993. 461 p.

2. The Science and Technology of Rubber/ Eds. by Mark J. E.. Erman B., Eirich F. / Amsterdam.: Elsevier. 2005. 743 p.

3. Donnet J. B., Vidal A. Chapter: Carbon black: Surface properties and interactions with elastomers. Pharmacy. Thermomechanics, Elastomers, Telechelics, Berlin, Heidelberg, New York, Tokyo: Spriger-Verlag, 2006, P. 103-127.

4. Tascon J. M. D. Novel Carbon Adsorbents Elsevier. 2012. 686 p.

5. Киселев А.В. Межмолекулярные взаимодействия в адсорбции и хроматографии. М. Высш. шк.. 1986. 360 с.

6. Липатов Ю.С. Физико-химические основы наполнения полимеров. М. Химия. $1991.259 \mathrm{c}$.

7. Eltekova N.A., Eltekov Y.A. // Carbon. 1993. Vol. 31. pp. 957-961.

8. Eltekova N.A., Razdyakonova G.I., Eltekov Y.A. // Pure Appl. Chem. 1993. Vol. 65. pp. 2217-2221.

9. Eltekova N.A., Berek D., Novak I., Belliardo F. // Carbon. 2000. Vol. 38. pp. 373-377.

10.Boehm H.P. // Carbon. 1994. Vol. 32. pp. 757-1032.

11.Zhang Yimin, Ge S., Tang B. et al. // Macromol. 2001. Vol. 34, pp. 7056-7065.

12.Zaborski M., Donnet J.B. // Macromol. Symp. 2003. Vol. 194(1). pp. 87-100.

13. Maafa D., Balard H., Donnet J.B. // Rubber Chem. Technol. 2007. Vol. 80(5). pp. 895906.

\section{References}

1. Carbon Black, Science and Technology, Eds. by Donnet J.B., Bansal R.C., Wang M.J., New York, Marcel Dekker, 1993, 461 p.

2. The Science and Technology of Rubber, Eds. by Mark J. E., Erman B., Eirich F., Amsterdam.: Elsevier, 2005, 743 p.

3. Donnet J.B., Vidal A., Chapter: Carbon black: Surface properties and interactions with elastomers. Pharmacy, Thermomechanics, Elastomers, Telechelics, Berlin, Heidelberg, New York, Tokyo: Spriger-Verlag, 2006, pp. 103127.
14.Эльтеков А.Ю., Эльтекова Н.А., Ролдугин В.И. // Коллоидн. Журн. 2007. Т. 69. С. 273-276.

15.Эльтекова Н.А., Соколова Н.П., Горбугов А.М., Эльтеков А.Ю. // Физикохим. поверхн.защита материал. 2013. Т. 49. С. 397401.

16.КиселевА.В., Малыгин, Ю.В., Строев В.Н., Эльтеков Ю.А. // Коллоидн. Журн. 1982. T. 44. С. 1051-1056.

17.Лихолобов В.А., Пьянова Л.Г., Бакланова О.Н., Седанова А.В. // Хим.тверд.топл. 2014. № 6. C. 57-66.

18.Суровикин Ю.В., Шайтанов А.Г., Дроздов В.А., Резанов И.В. и др. // Хим.тверд.топл. 2014. № 6. С. 67-78.

19.Эльтеков Ю.А., Шилов А.Д., Басов Б.К. // Высокомолек. Соед. 1982ю Т. 24 А. С. 652656

20.Boehm H.P. // Carbon. 2002. Vol. 40. pp. 145-149.

21.Эльтекова Н.А., Эльтеков Ю.А. // Журн.физ.хим. 2005. Т. 79. С. 725-728.

22.Эльтекова Н.А., Эльтеков Ю.А. // Журн.физ.хим. 2007. Т. 81. С. 699-703.

23.Эльтеков А.Ю., Эльтекова Н.А., Эльтеков Ю.А. // Сорбционные и хроматографические прочессы. 2014. Т. 14. № 6. С. 977987.

24.Eltekov A.Yu. // Сорбиионные и хроматографические проиессы. 2015. Т.15. № 3. С. 456-463.

4. J. M. D. Tascon, Novel Carbon Adsorbents, Elsevier, 2012, 686 p.

5. Kiselev A.V., Intermolecular interactions in adsorption and chromatography. M.: Higher School, 1986, $360 \mathrm{p}$.

6. Lipatov Yu.S. Physico-chemical bases of filling of polymers, M., Chemistry, 1991, $259 \mathrm{p}$.

7. Eltekova N.A., Eltekov Y.A., Carbon, 1993, Vol. 31, pp. 957-961.

8. Eltekova N.A., Razdyakonona G.I., Eltekov Y.A., Pure Appl. Chem., 1993, Vol. 65, pp. 2217-2221. 
9. Eltekova N.A., Berek D., Novak.I., Belliardo F, Carbon, 2000, Vol. 38, pp. 373377.

10. Boehm H.P., Carbon, 1994. Vol. 32, pp. 757-1032.

11. Zhang Yimin, Ge S., Tang B. et al., Macromol., 2001, Vol. 34, pp. 7056-7065.

12. Zaborski M., Donnet J.B., Macromol. Symp., 2003, Vol. 194(1), pp. 87-100.

13. Maafa D., Balard H., Donnet J.B., Rubber Chem. Technol., 2007, Vol. 80(5), pp. 895-906.

14. Eltekov A.Y., Eltekova N.A., Roldugin V.I., Colloid J., 2007, Vol. 69, pp. 248-251.

15. Eltekova N.A., Sokolova N.P., Gorbunov A.M., Eltekov A.Y., Phys. Chem. Surf. Protect. Mat., 2013. Vol. 49, pp. 421-425.

16. Kiselev A.V., Malygin Yu.V., Stroev V. N., Eltekov Yu.A., Kolloidn. Zurn., 1982, Vol. 44, pp. 1051-1056.

Эльтеков Антон Юрьевич - научный сотрудник Института физической химии и электрохимии им. А.Н.Фрумкина РАН (ИФХЭ РАН), Москва, тел. 4959554492.

Эльтекова Нина Александровна - к.х.н., старший научный сотрудник Института физической химии и электрохимии им. А.Н.Фрумкина РАН (ИФХЭ РАН), Москва, тел. 4959554611

Эльтеков Юрий Анатольевич - к.Х.н., старший научный сотрудник Института физической химии и электрохимии им. А.Н.Фрумкина РАН (ИФХЭ РАН), Москва, тел. 4959554492
17. Likholobov V.A., Pyanova L.G., Baklanova O.N., Sedanova A.V., Solid fuel chem., 2014, Vol. 48, pp. 382-391.

18. Surovikin Y.V., Shaitanov A.G., Drozdov V.A., Rezanov I.V. et a., Solid fuel chem., 2014, Vol. 48, pp. 392-403.

19. Shilov A.D. Basov B.K., Eltekov Yu.A., Polymer Sci. U.S.S.R., 1982. Vol. 24. pp. 728731.

20. Boehm H.P., Carbon, 2002, Vol. 40, pp. 145-149.

21. Eltekova N.A., Eltekov Yu.A., Rus. J. Phys.Chem., 2005, Vol. 79, pp. 620-623.

22. Eltekova N.A., Eltekov Yu.A., Rus. J. Phys. Chem., 2007, Vol. 81, pp. 602-606.

23. Eltekov A.Y., Eltekova N.A., Eltekov Y.A., Sorbtsionnye I khromatograficheskie protsessy, 2014, Vol. 14, No 6, pp. 977-987.

24. Eltekov A.Yu., Sorbtsionnye I khromatograficheskie protsessy, 2015, Vol. 15, No 3, pp. 456-463.

Eltekov Anton Yu. - researcher A.N.Frumkin Institute of Physical Chemistry and Electrochemistry, Russian Academy of Sciences, Moscow

Eltekova Nina A. - Ph.D., senior researcher A.N.Frumkin Institute of Physical Chemistry and Electrochemistry, Russian Academy of Sciences, Moscow, E-mail: ninel-elt@yandex.ru

Eltekov Yuri A. - Ph.D., senior researcher A.N.Frumkin Institute of Physical Chemistry and Electrochemistry, Russian Academy of Sciences, Moscow, E-mail:yur-elt@yandex.ru 